\title{
Rapor
}

\section{Ayaktan tanı ve tedavi başvurularında hasta başına kaç dakika ayrılmalıdır?}

\author{
Mahmut Yardıma, Erhan Eserb
}

\author{
a Yrd.Doç.Dr., Hacettepe Üniversitesi Tıp Fakültesi, Halk Sağlığı AD, Ankara \\ HASUDER - Sağlık Politikaları ve İstihdam ÇG üyesi \\ b Prof.Dr., Celal Bayar Üniversitesi Tıp Fakültesi, Halk Sağlı̆̆ AD, Manisa \\ HASUDER - Sağlık Politikaları ve İstihdam ÇG üyesi
}

Geliş tarihi: 15.12.2016, Kabul tarihi: 30.03 .2017

\begin{abstract}
Özet
$\mathrm{Bu}$ yazı, ayaktan tanı ve tedavi başvurularına ayrılan süreler ve bunun yol açtığı sonuçlar konusunda ulusal ve uluslararası düzeydeki bilgi birikimini derlemek ve ülkemizdeki ayaktan başvuru süreleri ile ilgili tartışmanın daha nesnel kanıtlar üzerinden yapılmasına olanak tanımak amacıyla hazırlanmıștır. Derlemede kaynaklar üç temel başlık altında incelenmiştir: İlk olarak birinci basamak sağlık hizmetlerindeki ayaktan tanı ve tedavi hizmetlerinde çeşitli ülkelerde, başvuru başına ayrılan süreler irdelenmiştir. İkinci başlık altında hizmet sunumunda ortaya çıkan nitel sorunlar incelenmiştir. Üçüncü başlık altında hekimler üzerindeki zaman baskısının, hekimlerin iş verimliliği, iş doyumu ve hasta hoşnutluğu üzerinde yol açtığı sonuçlar incelenmiștir. Uluslararası kaynaklara göre değerlendirildiğinde ayaktan başvuru sürelerinin 10 dakikadan az olmaması gerektiğini, ancak karmașık tıbbi durumlar göz önüne alındığında bu sürenin daha da artması gerektiği sonucuna varılabilir.
\end{abstract}

Anahtar kelimeler: Tanı-tedavi, muayene süresi, sağlık bakım kalitesi

\section{How many minutes should be reserved per patient in ambulatory care visits?}

\begin{abstract}
This report was prepared aiming to review national and international literature about outpatient visit length with leading consequences, as well as to stimulate an evidence based discussion on this topic in Turkey. The relevant literature was investigated under three topics: First topic was about the length of outpatient visits in different countries, the second topic was about quality of care.

Sorumlu Yazar: Yrd.Doç.Dr. Mahmut Yardım, Hacettepe Üniversitesi Tıp Fakültesi Halk Sağlığı Anabilim Dalı, 06100 Ankara, Tlf:0 50554473 32, E-posta: mahmut.yardim @ gmail.com

Copyright holder Turkish Journal of Public Health

This work is licensed under a Creative Commons Attribution-NonCommercial 4.0 International License. $(\mathrm{cc})$ EY-NC
\end{abstract}


The last topic was related with the effects of time pressure on health care providers such as efficiency, job satisfaction and patient satisfaction. International literature showed that outpatient visit length should not be less than 10 minutes and in complex situations this span should be expanded.

Key words: Outpatient care, visit length, quality of care

\section{Giriş}

Birinci basamak sağlık hizmetlerinde ayaktan tanı, tedavi ve koruyucu izlemlere ayrılan sürenin çeşitli nedenleri ve sonuçları olduğu özellikle ABD ve Birleşik Krallık çalışmalarında ortaya konmuştur. Türkiye'de ise ayaktan başvuru süreleri ile ilgili veriler ve bilimsel yayınlar son derecede sinırlıdır. Ayaktan tanı ve tedavi başvurularında hasta başına ayrılması gereken süre ile ilgili olarak Sağlık Bakanlığının 2. basamak kurumlarda hasta randevu sürelerini düşürmesi, hasta muayene (vizit) süreleri üzerine bir tartışmaya neden olmuştur. Türk Tabipleri Birliği, hekimlerin bir hastaya en az 15-20 dk zaman ayırmak gerektiğini, 3-5 dakikada yapılan muayenenin nitelikli sağlı hizmeti ile bağdaşmadığını ifade etmiş, Dünya Sağlık Örgütü'nün belirlediği en az hasta bakma süresinin 20 dakika olduğu, Sağlık Bakanlığının filli olarak hasta başına 10 dakikada bir randevu verdiğini ancak bu sürenin uygulamada çok daha kısa olduğunu belirtmiştir.1,2 Hastanelerde muayene randevularının 5 dakikaya indirildiğini ifade eden hekimlere ve meslek örgütlerine Sağlık Bakanlığı basın kanalıyla verdiği yanıtta, bu konuda çıkan haberlerin gerçeği yansıtmadığını, bu konuyla ilgili bir talimat ve genelgesi olmadığını, kaliteli bir muayene için en az 10 dakika, ihtiyaç duyulan branşlarda ise yeterli zamanın ayrılması gerektiğini belirtmiştir. ${ }^{3}$ Ancak bu açıklamaya karşın hastanelerde çalışan hekimler durumun böyle olmadığını, her on dakikaya iki randevu verilerek, görünen 10 dakika olsa da fiilen bu sürenin 5 dakika olduğunu belirtmişlerdir. Diğer taraftan halkın görüşlerini (her ne kadar toplumu temsil etmekten uzak bir örnek üzerinde olsa da) soran bir sosyal medya kaynağına göre halkın beklediği muayene süresi 10-20 dakika arasındadır.4
$\mathrm{Bu}$ yazı, ayaktan tanı ve tedavi başvurularına ayrılan süreler ve bunun yol açtığı sonuçlar konusunda ulusal ve uluslararası düzeydeki bilgi birikimini derlemek ve ülkemizdeki ayaktan başvuru süreleri ile ilgili tartışmanın daha nesnel kanıtlar üzerinden yapılmasına olanak tanımak amacıyla hazırlanmıştır.

\section{Yöntem}

Bu yazı, Türkiye'de ayaktan tanı ve tedavi hizmetlerine ayrilan ve ayrılması gereken süre ile ilgili tartışmalara $1 s ̧ ı k$ tutabilmek üzere, bugüne dek konuyla ilgili olarak yapılmış olan ve ulaşılabilen ulusal ve uluslararası kaynakların derlenmesiyle hazırlanmıștır. Uluslararası kaynak araştırmasında, Pubmed, Science Direct, Scopus vb. temel veri tabanlarına ek olarak Dünya Sağlık Örgütü, Dünya Aile Hekimleri Birliği (WONCA) ve İngiliz Hekimler Birliği ve İngiliz Ulusal Sağlık Sisteminin ilgili alt kuruluşu olan NICE'in rehberleri ve raporları taranmıștır. Derlemede kaynaklar üç temel başlık altında incelenmiştir:

1- Ağırlıklı olarak birinci basamak sağlık hizmetlerindeki ayaktan tanı ve tedavi hizmetlerinde çeşitli ülkelerde, başvuru başına ayrılan süreler irdelenmiştir.

2- Hizmet sunumunda ortaya çlkan nitel sorunlar ve

3- Hekimler üzerindeki zaman baskısının, hekimlerin iş verimliliği, iş doyumu ve hasta hoşnutluğu üzerinde yol açtığı sonuçlar tartışılmıştır.

Bu derlemede geçen "vizit", "konsültasyon" ve ayaktan tanı ve tedavi başvurusu" gibi terimler, birinci veya ikinci-üçüncü basamaktaki tanı ve sağaltım amaçlı ayaktan başvurular anlamında kullanılmıştır.

\section{Bulgular}

I. Ortalama ayaktan başvuru muayene (vizit) süreleri 
Sağlı hizmetlerinde ortalama ayaktan başvuru muayene süreleri ülkeden ülkeye değişiklikler göstermektedir. Aşağıda olabildiğince ülke ve tarih sırasına göre listelenen çalışmalarda, Amerika Birleşik Devletleri (ABD), Birleşik Krallık (İngiltere), Almanya, Japonya, Hollanda, İspanya, İsveç, İsviçre ve Sırbistan için ayaktan başvuru muayene süreleri izlenmektedir (Tablo 1).

Davidoff hastaların hekimin bilgi verici özelliğine büyük değer atfettiklerini belirttiği editöryal makalesinde, zaman içinde hekimlerin hastalarına ayırdıkları süreyle ilgili bir erozyondan söz etmektedir. Döneminde yapılmış araștırmalara atfen Birleşik Krallıkta genel pratisyenlerin hastalarına 7-9 dakika ayırdıklarını, bu sürenin ABD'de aile hekimleri için 20 dakika olduğunu belirtmektedir. ${ }^{5}$ Bundan bir yl sonra 1994'te yayımlanan ve hekimin hastasına ayırdığı sürenin bakım kalitesine etkisini inceleyen çalıșmanın sonuçları ABD'de hekimlerin bir saat içinde 3,6 (St.Sapma: 1,4) hasta muayene ettiklerini göstermiștir. Bu durumda hasta başına 16,7 dakika düşmektedir. ${ }^{6}$

Landau ve arkadaşları ABD'de 2007 yılında hastalar tarafindan optimal olarak kabul edilen muayene sürelerinin ortalamasını 15,4 dakika olarak hesaplamışlardır.7 ABD'de 2007 yılında yayımlanan bir çalışmada 392 hekim görüşmesinin videobant kayıtları çözümlendiğinde ortalama görüşme süresi 15,7 dakika bulunmuştur. Bu görüşmelerde median olarak altı konu başlığı hakkında bilgi alıșveriși gerçekleșmiștir. En uzun konuya yaklașık 5 dakika ayrılırken geri kalan konular için 1,1 dakika ayrılmıştır. ${ }^{8}$ Amerikan Ulusal Ayaktan Tibbi Hizmetler 2012 araştırmasına göre ortalama birinci basamak vizit süresi 22,6 dakikadır. ${ }^{9}$

Yine ABD'de 2016 yllında yapılan, 26 farklı uzmanlık dalından 19200 Hekimin katıldığı araştırmanın bulgularına göre ayaktan tanı ve tedavi başvuruları için hekimlerin yaklaşık \%60'ı 13-20 dakika arasında süre ayırmaktadır. Yaklaşık \%2227'si 13 dakikadan; \%5'i ise 10 dakikadan az süre ayırmaktadır. Uzman hekimlerin yaklaşık \%23'ü 20 dakikanın üstünde süre ayırmaktadır. ${ }^{10}$
ABD'de 1997 ile 2005 yılları arasında birinci basamak başvuruları yıllık 273 milyondan 338 milyona çıkmış; ortalama muayene süresi ise 18.0 dakikadan 20.8 dakikaya artmıştır. ${ }^{11}$ Altı Avrupa ülkesinde 2002 yılında yapılan kesitsel bir çalışmada birinci basamakta ortalama konsültasyon süreleri 7,6 dakika ile 15,6 dakika arasında değișmektedir. ${ }^{12}$ İsveç’te 1989 yılında yapılan bir çalışma genel pratisyen ortalama muayene süresini 21 dakika olarak saptamıştır.13 Japonya'da 2003 yılında yapılan çalışmada birinci basamak konsültasyon süresi 10,514, 2005 yılında yapılan bir diğer çalışmada ise 8,4 dakika olarak bulunmuştur. ${ }^{15}$

Yine Japonya'da yapılan daha yeni bir çalışmada, 2010 yılında 8 günlük bir gözlem sonrası 0 ile 93 yaş arası 263 birinci basamak hastasının ayaktan başvuru verileri incelendiğinde ortalama konsültasyon süresinin 6,1 dakika olduğu bulunmuștur. Bu süre erkek ve kadınlarda yaklaşık benzerdir ve yaşla birlikte bu süre artmaktadır. Başvuruların \%11,8'inde görüşme süresi 3 dakika veya altındadır. ${ }^{16}$

Üç ülkede 2010 yılında yapılan çalışmada Almanya, İngiltere ve ABD'de hekimlerin ilk başvuru hastasına sırasıyla 16/11/31 dakika ayırdıkları tespit edilmiştir (her ülkeden 128'er hekimle çalışılmış). $\mathrm{Bu}$ ülkelerde sıradan başvuru için yine sırasıyla 6/10/18 dakika ayrılmaktadır. Tam bir fizik muayene için ise sirasiyla 12/20/36 dakika ayrilmaktadır. ${ }^{17}$

Birleşik Krallık Tıp Birliği'nin 20062007 araştırmasında göre, Birleşik Krallık Ulusal Sağlık Sisteminde ortalama vizit (muayene) süreleri, 1993 yılında 8,4 dakikadan 2006 yılında 11,7 dakikaya çıkmıştır. ${ }^{18}$

Sirbistan'da genel pratisyenler birinci basamakta günde ortalama 40 hasta bakmaktadır. Buna göre ortalama muayene süresi 12 dakika kadardır. ${ }^{19}$

Ulaşabildiği kadarıyla Türkiye'den uluslararası literatürde yer alan tek çalışmada, Güldal ve arkadaşları ${ }^{20} 2002$ yılında İzmir'de, 110 sağlı ocağı içinden seçilen 30 sağlık ocağında 37 hekimin ilk 
kez sağlık ocağına başvuran 166 hastasını gözlemişlerdir. Ayrıca bu hekimleri de içeren 106 kişilik hekim grubuna bir anket de uygulanmıștır. Hekimlerin \%68,9'u ilk başvuru hastaları için yeterli sürenin 20 dakika, \%18,8'i 30 dakika olduğunu belirmişlerdir. Ancak sadece \%16'sı bu süreyi ayırabildiğini belirtmiștir. Hekimlerin \%73'ü 10 dakika ayırdıklarını söylemişlerdir. Gözlemde hekimlerin (37 hekimin) \%81,9'u ilk başvuru hastalarına 5 dakikadan daha az süre ayırmışlardır. Hekimlerin yarısı geçmiş ve şimdiki şikayete ait tıbbi öyküyü sormamış, aile öyküsü ve sistemik muayene \%80 hekim tarafından ihmal edilmiştir. Başvuruların \%63'ünde tıbbi kayıt tutulmamıştır.

Tablo 1. Yapılan farklı çalışmalarda farklı ülkeler için ortaya konan ayaktan başvuru muayene süreleri

\begin{tabular}{|c|c|c|c|c|c|c|}
\hline Ülke & Yll & Süre (dk) & Dal & Makale adı & Yazar & $\begin{array}{l}\text { Kaynak } \\
\text { No }\end{array}$ \\
\hline $\mathrm{ABD}$ & 1993 & 20 & Aile hekimi & Time. & Davidoff F. & 5 \\
\hline $\mathrm{ABD}$ & 1993 & 26 & $\begin{array}{c}\text { Genel } \\
\text { dahiliye }\end{array}$ & Time. & Davidoff F. & 5 \\
\hline $\mathrm{ABD}$ & 1994 & $\begin{array}{c}16,7 \\
\text { (Saat başına } 3,6 \\
\pm 1,4 \text { ) hasta) }\end{array}$ & $\begin{array}{l}\text { Birinci } \\
\text { basamak }\end{array}$ & $\begin{array}{l}\text { Practitioner productivity and } \\
\text { the product content of medical } \\
\text { care in publicly supported } \\
\text { health centers. }\end{array}$ & $\begin{array}{l}\text { Camasso, M. J. } \\
\text { Camasso, A. E. }\end{array}$ & 6 \\
\hline $\mathrm{ABD}$ & 2003 & 11,1 & $\begin{array}{l}\text { Ayaktan } \\
\text { başvuru }\end{array}$ & $\begin{array}{l}\text { Doctor-patient communication: } \\
\text { a comparison of the USA and } \\
\text { Japan. }\end{array}$ & $\begin{array}{l}\text { Ohtaki S, Ohtaki T, } \\
\text { Fetters MD. }\end{array}$ & 14 \\
\hline $\mathrm{ABD}$ & 2007 & $\begin{array}{c}15,4 \\
\text { (hastaların } \\
\text { tercih ettiği } \\
\text { optimal ortalama } \\
\text { süre) }\end{array}$ & $\begin{array}{c}\text { Birinci } \\
\text { basamak }\end{array}$ & $\begin{array}{l}\text { Patients' views on optimal visit } \\
\text { length in primary care. }\end{array}$ & $\begin{array}{l}\text { Landau DA, Bachner } \\
\text { YG, Elishkewitz K, } \\
\text { Goldstein } \\
\text { Barneboim E. }\end{array}$ & 7 \\
\hline $\mathrm{ABD}$ & 2007 & 15,7 & & $\begin{array}{l}\text { Time allocation in primary care } \\
\text { office visits. }\end{array}$ & $\begin{array}{lr}\text { Tai-Seale } & \text { M, } \\
\text { McGuire TG, Zhang } \\
\text { W. }\end{array}$ & 8 \\
\hline $\mathrm{ABD}$ & 2009 & 20,8 & $\begin{array}{c}\text { Birinci } \\
\text { basamak }\end{array}$ & $\begin{array}{l}\text { Primary care visit duration and } \\
\text { quality: does good care take } \\
\text { longer? }\end{array}$ & $\begin{array}{l}\text { Chen LM, Farwell } \\
\text { WR, Jha AK. }\end{array}$ & 11 \\
\hline $\mathrm{ABD}$ & 2010 & $\begin{array}{l}18 \\
\text { (ilk başvuru için } \\
32 \text { ) }\end{array}$ & $\begin{array}{l}\text { Ayaktan } \\
\text { başvuru }\end{array}$ & $\begin{array}{l}\text { It's about time: physicians' } \\
\text { perceptions of time constraints } \\
\text { in primary care medical practice } \\
\text { in three national healthcare } \\
\text { systems. }\end{array}$ & $\begin{array}{l}\text { Konrad TR, Link CL, } \\
\text { Shackelton RJ, et al. }\end{array}$ & 17 \\
\hline $\mathrm{ABD}$ & 2012 & 22,6 & $\begin{array}{c}\text { Birinci } \\
\text { basamak }\end{array}$ & $\begin{array}{l}\text { National Ambulatory Medical } \\
\text { Care Survey. }\end{array}$ & $\begin{array}{l}\text { Ashman JJ, Hing E, } \\
\text { Talwalkar A, }\end{array}$ & 9 \\
\hline $\mathrm{ABD}$ & 2016 & $\begin{array}{l}13-20 \\
\text { (Hekimlerin } \\
\left.\% 60^{\prime} 1\right)\end{array}$ & $\begin{array}{c}\text { Farklı } \\
\text { uzmanlık } \\
\text { dallarından }\end{array}$ & $\begin{array}{l}\text { Medscape Physician } \\
\text { Compensation Report. }\end{array}$ & Peckham C. & 10 \\
\hline Almanya & 2002 & $7,6(4,3)^{*}$ & $\begin{array}{c}\text { Genel } \\
\text { pratisyen }\end{array}$ & $\begin{array}{l}\text { Consultation length in general } \\
\text { practice: cross sectional study in } \\
\text { six European countries. }\end{array}$ & $\begin{array}{l}\text { Deveugele M, Derese } \\
\text { A, van den Brink- } \\
\text { Muinen A, Bensing J, } \\
\text { De Maeseneer J. }\end{array}$ & 12 \\
\hline Almanya & 2010 & $\begin{array}{c}6 \\
\text { (ilk başvuru için } \\
16)\end{array}$ & $\begin{array}{l}\text { Ayaktan } \\
\text { başvuru }\end{array}$ & $\begin{array}{l}\text { It's about time: physicians' } \\
\text { perceptions of time constraints } \\
\text { in primary care medical practice } \\
\text { in three national healthcare } \\
\text { systems. }\end{array}$ & $\begin{array}{l}\text { Konrad TR, Link CL, } \\
\text { Shackelton RJ, et al. }\end{array}$ & 17 \\
\hline
\end{tabular}


Tablo 1'in devamı

\begin{tabular}{|c|c|c|c|c|c|}
\hline Belçika & 2002 & $15,0(7,2)^{*}$ & $\begin{array}{c}\text { Genel } \\
\text { pratisyen }\end{array}$ & $\begin{array}{l}\text { Consultation length in general practice: } \\
\text { cross sectional study in six European } \\
\text { countries. }\end{array}$ & $\begin{array}{l}\text { Deveugele } \mathrm{M} \text {, Derese } \mathrm{A}, 12 \\
\text { van den Brink-Muinen A, } \\
\text { Bensing J, De Maeseneer J. }\end{array}$ \\
\hline Hollanda & 2002 & 10,2 & $\begin{array}{r}\text { Ger } \\
\text { prati }\end{array}$ & $\begin{array}{l}\text { Consultation length in general practice: } \\
\text { cross sectional study in six European } \\
\text { countries. }\end{array}$ & $\begin{array}{l}\text { Deveugele M, Derese A, } 12 \\
\text { van den Brink-Muinen A, } \\
\text { Bensing J, De Maeseneer J. }\end{array}$ \\
\hline İngiltere & 1993 & $7-9$ & & Time. & Davidoff F. \\
\hline İngiltere & 2002 & 9,4 & & $\begin{array}{l}\text { Consultation length in general practice: } \\
\text { cross sectional study in six European } \\
\text { countries. }\end{array}$ & $\begin{array}{l}\text { Deveugele } \mathrm{M} \text {, Derese A, } 12 \\
\text { van den Brink-Muinen A, } \\
\text { Bensing J, De Maeseneer J. }\end{array}$ \\
\hline İngiltere & 2007 & 11,7 & & $\begin{array}{l}\text { 2006/07 UK General Practice Workload } \\
\text { Survey. }\end{array}$ & $\begin{array}{l}\text { Information Centre Part } 18 \\
\text { of the Government } \\
\text { Statistical Service. }\end{array}$ \\
\hline İngiltere & 2010 & $\begin{array}{l}10 \\
\text { (ilk } \\
\text { başvuru }\end{array}$ & $n$ & $\begin{array}{l}\text { It's about time: physicians' perceptions of } \\
\text { time constraints in primary care medical } \\
\text { practice in three national healthcare } \\
\text { systems. }\end{array}$ & $\begin{array}{l}\text { Konrad TR, Link CL, } \\
\text { Shackelton RJ, et al. }\end{array}$ \\
\hline İspar & 2002 & 7,8 & $\begin{array}{r}\text { Gen } \\
\text { pratis }\end{array}$ & $\begin{array}{l}\text { Consultation length in general practice: } \\
\text { cross sectional study in six European } \\
\text { countries. }\end{array}$ & $\begin{array}{l}\text { ele M, Derese A, } 12 \\
\text { n Brink-Muinen A, } \\
\text { g J, De Maeseneer J. }\end{array}$ \\
\hline İsveç & 1989 & 21 & & $\begin{array}{l}\text { of consultations in general practice } \\
\text { den: views of doctors and patients. }\end{array}$ & $\begin{array}{l}\text { on, S. O. } \\
\text { n, B. }\end{array}$ \\
\hline İsviçre & 2002 & $15,6(8$ & $\begin{array}{r}\mathrm{G} \\
\text { pra }\end{array}$ & $\begin{array}{l}\text { Consultation length in general practice: } \\
\text { cross sectional study in six European } \\
\text { countries. }\end{array}$ & $\begin{array}{l}\text { Deveugele M, Derese A, } 12 \\
\text { van den Brink-Muinen A, } \\
\text { Bensing J, De Maeseneer J. }\end{array}$ \\
\hline Japonya & 2003 & 10,5 & & $\begin{array}{l}\text { Doctor-patient communication: } \\
\text { comparison of the USA and Japan. }\end{array}$ & $\begin{array}{l}\text { Ohtaki S, Ohtaki T, Fetters } 14 \\
\text { MD. }\end{array}$ \\
\hline Japonya & 2005 & 4 & $\begin{array}{l}\text { Genel } \\
\text { pratisyen }\end{array}$ & $\begin{array}{l}\text { Patient contribution to the medical } \\
\text { dialogue and perceived patient- } \\
\text { centeredness. An observational study in } \\
\text { Japanese geriatric consultations. }\end{array}$ & $\begin{array}{l}\text { Ishikawa H, Hashimoto } \mathrm{H}, \\
\text { Roter DL, Yamazaki Y, } \\
\text { Takayama T, Yano E. }\end{array}$ \\
\hline Japonya & 2010 & 6,1 & $\begin{array}{r}\text { Kırsa } \\
\text { kli }\end{array}$ & $\begin{array}{l}\text { Truth or fallacy? Three hour wait for three } \\
\text { minutes with the doctor: Findings from a } \\
\text { private clinic in rural Japan. }\end{array}$ & $\begin{array}{l}\text { Wooldridge AN, Arato N, } 16 \\
\text { Sen A, Amenomori M, } \\
\text { Fetters MD. }\end{array}$ \\
\hline Sirbistan & 2016 & 12 & & $\begin{array}{l}\text { Evaluation of the organization and the } \\
\text { provision of primary care in Serbia. }\end{array}$ & Dünya Sağlı \\
\hline
\end{tabular}

*Standart sapma değeri parantez içinde verilmiştir.

\section{Hizmet sunumunda ortaya çıkan nitel sorunlarla ilgili sınırlı sayıda çalışmalar}

Ayaktan tanı ve tedavi başvurularında yetersiz süre ayrılmasının hizmetin niteliği üzerinde de olumsuz etkilerinin olduğu, çalışmaların yoğunlaştığı, ABD, Birleşik Krallık ve Kanada'da gösterilmiştir. $\mathrm{Bu}$ çalışmalardan bir kaç örneğe göz atacak olursak:

Kanada'da yapılan bir çalışmaya göre 15 dakikadan kısa zaman ayırma, uygun olmayan reçete yazımına ve gastrointestinal sistem yan etkilerinin iyi yönetilememesine yol açabilmektedir. ${ }^{21}$ İngiltere'de yapılan çalışmalarda, hasta başına ayrılan sürenin 6,7 dakikadan 8,2 dakikaya çıkarılması durumunda daha iyi öykü alınabildiği, hastalık taramalarının (hipertansiyon vb.) daha etkin yapılabildiği bildirilmiștir. ${ }^{22-24}$

ABD'de yapılan bir kohort çalışması sonuçlarına göre, saatte bakılan hasta sayısı 3'ü aşarsa (vizit süresi 20 dakikanın altına düşerse) bağışıklama uygulamaları ve risk faktörleri ile ilgili sağlıklı öykü alabilme aksamaktadır. Saatte bakılan hasta sayısı 3,8'i geçerse uzman sevklerinde önemli artışlar gözlenmektedir. ${ }^{6}$

ABD'de 2009 yılında yapılan bir çalışmada birinci basamak hekimlerinin vizit sürelerinin 1997-2005 döneminde artıș gösterdiği; hizmet niteliğinin vizit süresinden orta derecede etkilendiği, koruyucu tarama vb. hizmetlerin ek süre gerektirdiği ancak uygun ilaç tedavisinin 
vizit süresinden etkilenmediği gösterilmiştir. ${ }^{11}$

2016 yllında ABD Detroit eyaletinde 64 birinci basamak hizmet başvurusu üzerinden yapılan çalışmada, kısa sürelerin koruyucu hizmetlere ayrılan süreleri kısalttığı özellikle de elektronik olmayan hasta kayıt sistemlerinin kullanıldığı durumlarda koruyucu hizmetlere daha az zaman ayrıldığı gösterilmiştir. ${ }^{25}$

$\begin{array}{rlrl}\text { ABD'de } & 1996 \text { yılında yapılan bu } \\ \text { ülkedeki } & \text { sağlık } & \text { hizmetlerinin }\end{array}$ değerlendirilmesi amacıyla yapılan ilk çalıșmalardan birinde, haftada 70 hastaya kadar ayaktan tanı ve tedavi başvurusu yapılan birinci basamak kurumlarında klinik kararların daha doğru ve sağlıklı olduğu gösterilmiştir ${ }^{26}$.

ABD'de malpraktis geçmişi olan hekimlerin muayene sürelerinin diğer hekimlerden daha kısa olduğu görülmüştür27; 1997 yılında, 59 birinci basamak kliniğinde yayımlanan çalışmada hasta başına ayrılan sürenin malpraktis davası açlan hekimlerde 15,0, dava açlmayan hekimlerde 18,3 dakika olduğu gözlenmiştir. ${ }^{28}$

\section{Hasta-hekim ilişkileri, hasta memnuniyeti ve hekimlerin iş doyumu}

Araştırmalar, hekimlerin doyumsuzluğundaki temel değișkenin zaman baskısı olduğunu, hekimlerin doyumu/doyumsuzluğunun ise hastaların doyumunu/doyumsuzluğunu da doğrudan tetikleyeceğini göstermektedir.

ABD'de 2000 yılında yaplan 16 birinci basamak kurumunda hastaların muayene süreleri ile ilgili algılarının değerlendirildiği bir çalışmada hastaların muayene öncesi süre beklentileri 20 dakika ya da daha uzundur. ${ }^{29}$ Ayrica ABD'de yapılan diğer çalışmalar göstermiştir ki saatte üç veya dörtten fazla hasta bakılması, muayene içeriğinin kısıtlanmasına ve hasta memnuniyetinin azalmasina yol açmaktadır. ${ }^{30}$

Yine İngiltere'de ayaktan başvurularda beş dakika ayrılan hastalar, 10 ve 15 dakika ayrılan hastalara göre kendilerine yeterli zaman ayrılmadığını belirtmişlerdir. ${ }^{22,31}$

ABD'de bir üniversite fizik tedavi merkezine başvuran hastaların hekimden bilgi alma (soru sorma) istekleri, ortanca muayene süresi 18 dakikanın üstüne çıkınca artmaktadır. ${ }^{32}$

Birleşik Krallık Tıp Birliği tarafından 2015 yılında Birleşik Krallıkta (UK) yapılan Genel Pratisyenler Çalışmasına göre, birinci basamak hizmetlerin temel unsurlarını gerçekleştirebilmek için hekimlerin sıraladıkları ilk beş faktör içinde "daha uzun konsültasyon/muayene süresi" $\% 70$ ile ikinci sıradadır. Birinci sırada ise daha iyi ücretler gelmektedir. Hekimlere, verdikleri hizmetin niteliğini ve mesleki kariyerlerini etkileyen "en olumsuz" faktörler sorulduğunda ise, \%71 ile ilk sırada iş yükü gelirken, üçüncü sırayı \%43 ise hastalara yetersiz zaman ayırma almıştır. $\mathrm{Bu}$ çalışmada, UK'de genel pratisyenlerin \%67'si 10 dakikalık muayene süresini yetersiz bulduklarını belirtmişlerdir. ${ }^{33}$

Son olarak hastaların optimal vizit süreleri ile ilgili görüşlerinin değerlendirildiği bir ABD çalışmasında özellikle genç hastalar için hasta hoşnutluğunun, vizit süreleri ile yüksek düzeyde pozitif ilişki içinde olduğu; optimal sürenin ise hastalar için 15,4 dakika olduğu saptanmıştır. ${ }^{7}$

\section{Tartışma}

Bu yazı başvuru sayılarındaki artışın ve hekime dayatılan kısa zamanda çok hasta muayene etme baskısının nedenlerine girmeden, sağllk sistemleri oturmuş ülkelerdeki örnekleri kıyaslayarak okuyucuya sağlık hizmeti almak için başvuranlara hekimlerin ne kadar süre ayırması gerektiği konusunda ipuçları vermek amacıyla hazırlanmıştır. Ulaşılan yayınlar, bu sürelerin ülkeler arasında önemli farklılıkları olduğunu göstermektedir. Ancak hem hekimlerde hem de başvuranlarda, mesleki doyum ve hasta tatmini açlarından daha uzun konsültasyon sürelerinin tercih edildiği görülmektedir.

Ayaktan ziyaret (muayene) süreleri açısından, izlendiği gibi ABD ile diğer Batılı gelişmiş ülkeler arasında önemli farklılıklar 
mevcuttur. ABD'de bu süreler genellikle 20 dakika etrafında dolaşırken Avrupa ve Japonya'da, bazı istisnalar dışında, fiilen bu sürenin neredeyse yarısı kadar (en fazla 10 dakika) zaman ayrılabildiği izlenmektedir. Ancak bu süre kısıtlamasından özelikle UK hekimlerinin büyük yakınmaları olduğunu gözlüyoruz. Birinci basamak ayaktan başvuru epizotlarını derleyen bu çalışmanın verilerinden, Türkiye'de önerilen 20 dakikalık optimum muayene süresinin $\mathrm{ABD}$ çalışmalarına atfen kabul gördügünü anlıyoruz. Daha kısa süreli ziyaretin olduğu ülkelerde bu sürelerden büyük yakınmaların olduğu dikkate alındığında bir hedef olarak önerilen 20 dakikalık sürenin uygun olduğunu düşünebiliriz. Birleşik Krallık Ulusal Sağlık Sistemi hastaların birinci basamakta kendilerine 8-10 dakika zaman ayrılmasını beklemelerini önerirken (Nisan 2014'e dek UK'de sabit muayene süresi 10 dakikadır), İngiliz Tıp Birliği (BMA) , UK Ulusal Sağlık Sisteminde ortalama muayene sürelerinin 10 dakikadan 15 dakikaya çıkarılmasını istemektedir. ${ }^{34}$ BMA, yaşlanan ve fazla kiloluluk ve obezitenin hızla arttığ toplumda birçok hastanın muayene için fazladan zamana gereksinimi olduğunu bu önerilerinin nesnel gerekçesi olarak sunmaktadır. BMA, Birinci Basamak Güvenli Çalışma ilkelerine göre genel pratisyenlerin haftanın 5 günü dikkate alındığında toplam olarak hasta muayene sayısının 155'i aşmamasını önermektedir. ${ }^{34}$ Yani BMA'ya göre, günde bakılacak hasta sayısı 23'ü geçmemelidir.

$\mathrm{Bu}$ raporun bir önemli sinırlılı̆̆ kaynakçadaki ağırlığı nedeniyle çoğunlukla birinci basamak başvuru süreleri ile yetinilmiş olmasıdır. Doğaldır ki ayrılan bu süreler, bașta yaș olmak üzere, cinsiyet (kadınlara daha uzun süreler ayrıldığı da bildirilmektedir ${ }^{35}$ ) eğitim ${ }^{36}$ ve en önemlisi de sağlık sorunları ve bunların içinde en önemlisi olan süreğen sağlık sorunlarının varlığından etkilenmektedir. Çoklukla süreğen sağllk sorunlarına yönelik hizmet veren 2 . ve 3 . basamak kurum başvurularında ayrılan sürenin birinci basamaktan daha uzun olduğu da bildirilmiştir. ${ }^{37}$ Kronik bedensel sağlık sorunu olan bireylerin hastanelerdeki ayaktan başvuruları ve özellikle de psikiyatrik morbiditeler için ayrılan süreler çok daha uzundur. Diğer taraftan, ilk başvuran hastalara (hizmet basamağ ne olursa olsun) daha uzun süreler ayrıldığı veya ayrılması gerektiği; bu sürelerde koruyucu izlem ziyaretleri (risk grubu izlemlerinde ayrılan süre) ve hasta takip ziyaretleri ile epizodik sağlık sorunu başvurularında farklı süreler olduğu iddia edilmektedir. Bu derlemede, söz konusu bu farklıklar irdelenmemiştir. Ayrıca hizmetlerde kullanılan kayıt teknolojisinin de etkili olduğu, elektronik kayıt sistemlerinin kullanımının birinci basamakta hastalara ayrılan süreleri de artırdığı bildirilmektedir. $^{25}$

\section{Sonuç ve öneriler}

$\mathrm{Bu}$ veriler ışığında, yeterli sürenin ayrılmadığı ayaktan tanı ve tedavi başvurularının, hekim ve hasta doyumunu düşürdügü; iyi bir öykü almaya engel olabildiği, bunun da sağlık sorununun hekim tarafından iyi yönetilmemesine neden olacağı sonucu çıkarılabilir. $\mathrm{Bu}$ veriler ışığında, son günlerde gündeme gelen devlet hastanesi ayaktan tanı ve tedavi başvurularında randevuların ortalama beş dakika süre dikkate alınarak verilmesinin bakım kalitesini bozacağı aşikardır. Doğru tanı ve tedavinin aksaması hastaları tekrar sağlık kurumlarına başvurmak mecburiyetinde birakacak ve bu durum bir kısır döngüyle başvuru sayısını ve zaman baskısını arttıracaktır. Türkiye'de gerek birinci basamakta gerekse ikinci ve üçüncü basamak sağllk hizmetlerinde ayaktan başvurular için ayrılan sürelerle ilgili ayrıntılı analizler yapılmalı ve veriler konu ile ilgili bilim kamuoyu ile paylaşılmalıdır. İdeal sürelere ilk aşamada ulaşılamasa da optimum kararlar bu veriler ışığında oluşturulmalıdır. Uluslararası kaynaklara göre değerlendirildiğinde ayaktan başvuru sürelerinin 10 dakikadan az olmaması gerektiğini, ancak karmaşık tıbbi durumlar göz önüne alındığında bu sürenin daha da artması gerektiği sonucuna varılabilir.

Ülkemizde sevk zincirinin işletilmesi, aile hekiminden sevk edilmeden hastane polikliniğine başvuruların önünün kesilmesi mutlaka gereklidir. Bu girişim, hastanelere ayaktan başvuru sayılarını düşürerek 
bașvurulara ayrılan süreleri de arttıracaktır. Şu an aile hekimi başvurularının ücretsiz olması şeklinde bir finansal teşvik olsa da bu yeterli olmamaktadır. Kaliteli bir sağlık hizmeti sunma konusunda tüketici örgütleri, sağlık meslek örgütleri dahil sivil toplumun katılımı olmadan yukarıdan alınacak kararlar, değişik sıkıntılar yaratarak başarısız olmaya mahkumdur. Toplumun mutluluğu ve sağlığı adına, ülke kaynaklarının israf edilmemesi adına bu konunun ivedilikle ele alınması gerekmektedir.

\section{Kaynaklar}

1. Türk Tabipleri Birliği. TTB 2014-16 Yillık Çalışma Raporu. 2016.

2. T24 İnternet Haber Gazetesi. 'Doktorlar hastalara 5 dakika ayırarak günde 150 hasta bakmak zorunda biraklliyor'. 2013; http://t24.com.tr/haber/doktorlarhastalara-5-dakika-ayirarak-gunde150-hasta-bakmak-zorundabirakiliyor,245512. Erişim Tarihi 20 Şubat, 2017.

3. Medimagazin. Bakanlıktan 5 dakika açlklaması. 2016; http://www.medimagazin.com.tr/he kim/saglik-bak/tr-bakanliktan-5dakika-aciklamasi-2-13-72058.html Erişim Tarihi 20 Şubat, 2017.

4. Doktorlar Sitesi. Kamuoyuna Sorduk "Bİr Hekİm Bİr Hastaya Ortalama Kaç Dk. Ayirmalidir?” İște Cevaplar. 2015; http://doktorlarsitesi.net/2015/07/ 13/kamuoyuna-sorduk-bir-hekimbir-hastaya-ortalama-kac-dkayirmalidir-iste-cevaplar/. Erişim Tarihi 20 Şubat, 2017.

5. Davidoff F. Time. Ann Intern Med. 1997;127(6):483-485.

6. Camasso MJ, Camasso AE. Practitioner productivity and the product content of medical care in publicly supported health centers. Soc Sci Med. 1994;38(5):733-748.

7. Landau DA, Bachner YG, Elishkewitz K, Goldstein L, Barneboim E. Patients' views on optimal visit length in primary care. J Med Pract Manage. 2007;23(1):12-15.

8. Tai-Seale M, McGuire TG, Zhang W. Time allocation in primary care office visits. Health Serv Res. 2007;42(5):1871-1894.

9. Ashman JJ, Hing E, Talwalkar A, National Ambulatory Medical Care Survey (U.S.), National Center for Health Statistics (U.S.). Variation in physician office visit rates by patient characteristics and state, 2012. NCHS data brief no 212. Hyattsville, Md.: U.S. Department of Health and Human Services, Centers for Disease Control and Prevention, National Center for Health Statistics,; 2015.

10. Peckham C. Medscape Physician Compensation Report. 2016; http://www.medscape.com/features /slideshow/compensation/2016/pu blic/overview?src=wnl_physrep_160 401_mscpedit\&uac $=232148 \mathrm{CZ \& impI}$ $D=1045700 \&$ faf $=1 \#$ page $=26$. Erişim Tarihi 20 Şubat, 2017.

11. Chen LM, Farwell WR, Jha AK. Primary care visit duration and quality: does good care take longer? Arch Intern Med. 2009;169(20):18661872.

12. Deveugele $M$, Derese $A$, van den Brink-Muinen A, Bensing J, De Maeseneer J. Consultation length in general practice: cross sectional study in six European countries. BMJ. 2002;325(7362):472.

13. Andersson SO, Mattsson B. Length of consultations in general practice in Sweden: views of doctors and patients. Fam Pract. 1989;6(2):130134.

14. Ohtaki S, Ohtaki T, Fetters MD. Doctor-patient communication: a comparison of the USA and Japan. Fam Pract. 2003;20(3):276-282.

15. Ishikawa $H$, Hashimoto $H$, Roter DL, Yamazaki Y, Takayama T, Yano E. Patient contribution to the medical dialogue and perceived patientcenteredness. An observational study 
in Japanese geriatric consultations. $J$ Gen Intern Med. 2005;20(10):906910.

16. Wooldridge AN, Arato N, Sen A, Amenomori M, Fetters MD. Truth or fallacy? Three hour wait for three minutes with the doctor: Findings from a private clinic in rural Japan. Asia Pac Fam Med. 2010;9(1):11.

17. Konrad TR, Link CL, Shackelton RJ, et al. It's about time: physicians' perceptions of time constraints in primary care medical practice in three national healthcare systems. Med Care. 2010;48(2):95-100.

18. Information Centre Part of the Government Statistical Service. 2006/07 UK General Practice Workload Survey 2007; http://content.digital.nhs.uk/catalog ue/PUB01028/gp-work-serv-rep.pdf. Erişim Tarihi 9, 12, 2016.

19. WHO. Evaluation of the organization and the provision of primary care in Serbia. 2016; http://www.euro.who.int/_data/ass ets/pdf_file/0005/128849/e94554.p df. Erişim Tarihi 20 Şubat, 2017.

20. Guldal D, Ulusel B, Ozcakar N, Yeniceri N, Dontlu C. The challenge of clinical interviewing and physical examination performance for general practitioners in Turkey. Fam Med. 2005;37(5):354-359.

21. Lowes RL. Are you expected to see too many patients? Med Econ. 1995;72(6):52-53, 57-59.

22. Morrell DC, Evans ME, Morris RW, Roland MO. The "five minute" consultation: effect of time constraint on clinical content and patient satisfaction. $\mathrm{Br}$ Med J (Clin Res Ed). 1986;292(6524):870-873.

23. Roland MO, Bartholomew J, Courtenay MJ, Morris RW, Morrell DC. The "five minute" consultation: effect of time constraint on verbal communication. $\mathrm{Br}$ Med J (Clin Res Ed). 1986;292(6524):874-876.
24. Wilson A, McDonald P, Hayes L, Cooney J. Health promotion in the general practice consultation: a minute makes a difference. BMJ. 1992;304(6821):227-230.

25. Lafata JE, Shay LA, Brown R, Street RL. Office-Based Tools and Primary Care Visit Communication, Length, and Preventive Service Delivery. Health Serv Res. 2016;51(2):728-745.

26. Kaplan SH, Greenfield S, Gandek B, Rogers WH, Ware JE, Jr. Characteristics of physicians with participatory decision-making styles. Ann Intern Med. 1996;124(5):497504.

27. Hickson GB, Clayton EW, Entman SS, et al. Obstetricians' prior malpractice experience and patients' satisfaction with care. JAMA. 1994;272(20):15831587.

28. Levinson W, Roter DL, Mullooly JP, Dull VT, Frankel RM. Physicianpatient communication. The relationship with malpractice claims among primary care physicians and surgeons. JAMA. 1997;277(7):553559.

29. Lin CT, Albertson GA, Schilling LM, et al. Is patients' perception of time spent with the physician a determinant of ambulatory patient satisfaction? Arch Intern Med. 2001;161(11):1437-1442.

30. Dugdale DC, Epstein R, Pantilat SZ. Time and the patient-physician relationship. J Gen Intern Med. 1999;14 Suppl 1:S34-40.

31. Ridsdale L, Carruthers M, Morris R, Ridsdale J. Study of the effect of time availability on the consultation. $J R$ Coll Gen Pract. 1989;39(329):488491.

32. Beisecker AE, Beisecker TD. Patient information-seeking behaviors when communicating with doctors. Med Care. 1990;28(1):19-28.

33. Association BM. The future of General Practice. National survey of GPS 2015; https://www.bma.org.uk/collective- 
voice/committees/generalpractitioners-committee/gpcsurveys/future-of-general-practice. Erişim Tarihi 7 Aralık, 2016.

34. Haroon Siddique. GP appointments should be five minutes longer, says BMA. 2016; https://www.theguardian.com/socie ty/2016/aug/28/doctorappointments-15-minutes-bmaoverweight-population. Erişim Tarihi 11, 12, 2016.

35. Tabenkin H, Goodwin MA, Zyzanski SJ, Stange KC, Medalie JH. Gender differences in time spent during direct observation of doctor-patient encounters. J Womens Health (Larchmt). 2004;13(3):341-349.

36. Fiscella K, Goodwin MA, Stange KC. Does patient educational level affect office visits to family physicians? J Natl Med Assoc. 2002;94(3):157-165.

37. Shaw MK, Davis $S A$, Fleischer AB, Feldman SR. The duration of office visits in the United States, 1993 to 2010. Am J Manag Care. 2014;20(10):820-826. 